\title{
Unusual Presentation of Second Branchial Cleft Cyst: Case Reports and Literature Review
}

\author{
Shin Chul Jung, Hun Jae Oh, Nam Yong Do, and Jun Hee Park \\ Department of Otorhinolaryngology-Head and Neck Surgery, Chosun University School of Medicine, Gwangju, Korea
}

\author{
부인두에 발생한 제2형 새열낭종 3 예 \\ 정신철 · 오훈재 · 도남용 · 박준희 \\ 조선대학교 의학전문대학원 이비인후과학교실
}

\author{
Received January 19, 2015 \\ Revised February 24, 2015 \\ Accepted March 10, 2015 \\ Address for correspondence \\ Jun Hee Park, MD \\ Department of Otorhinolaryngology- \\ Head and Neck Surgery, \\ Chosun University \\ School of Medicine, \\ 365 Pilmun-daero, Dong-gu, \\ Gwangju 61453, Korea \\ Tel $+82-62-220-3775$ \\ Fax +82-62-225-2702 \\ E-mail entjh28@chosun.ac.kr
}

\begin{abstract}
Second branchial cleft cysts are the most common neck masses found in adults. However, the parapharyngeal presence of branchial cleft cyst is very rare. We report three cases of parapharyngeal branchial cleft cyst in adults. They suffered from frequent oropharyngeal infection or abscess. We performed a transoral resection without any surgical complications. Biopsy revealed a squamous lined epithelial wall with lymphoid aggregation, which is characteristic of branchial cleft cyst. No evidence of recurrence was observed in 2 years.
\end{abstract}

Korean J Otorhinolaryngol-Head Neck Surg 2016;59(2):140-4

Key Words Branchial cleft cyst $\cdot$ Neck mass $\cdot$ Parapharynx.

\section{Introduction}

Second branchial cleft cyst is the most common among branchial anomalies. ${ }^{1)}$ It occurs as cervical sinus that temporarily appears in the process of branchial apparatus developing into various structures of neck is not closed but remains to exist. The second branchial cleft cyst is characteristically known to have the shape of cystic neck mass that is located from lateral neck to anterior border of sternocleidomastoid muscle. ${ }^{2,3)}$ However, there is a very rare case where second branchial cleft cyst appears in the form of cystic mass that is located in parapharyngeal space. The authors completely removed cysts in intraoral approach for cystic mass in parapharyngeal space that recurred in the form of abscess for several times among adults before experiencing the three cases where second branchial cleft cyst was diagnosed in histopathological examination. Therefore, the authors report the cases along with the literal review.

\section{Case}

\section{Case I}

A male patient aged 51 was transferred to the hospital for main complaints of swelling sensation of pharynx, dysphagia and throat pain that had continued for several months. The patient visited other hospital seven months ago to receive the examination that showed the findings of left pharyngeal wall protrusion, injection and tenderness. The patient underwent the procedure of incision and drainage for two times under the diagnosis of left parapharyngeal abscess. When the patient visited this hospital, physical examinations showed that lateral wall of left oropharynx was severely protruded and pushed to the center and that uvula and left tonsil were dislocated to the right lower part respectively due to protrusion of the lateral 

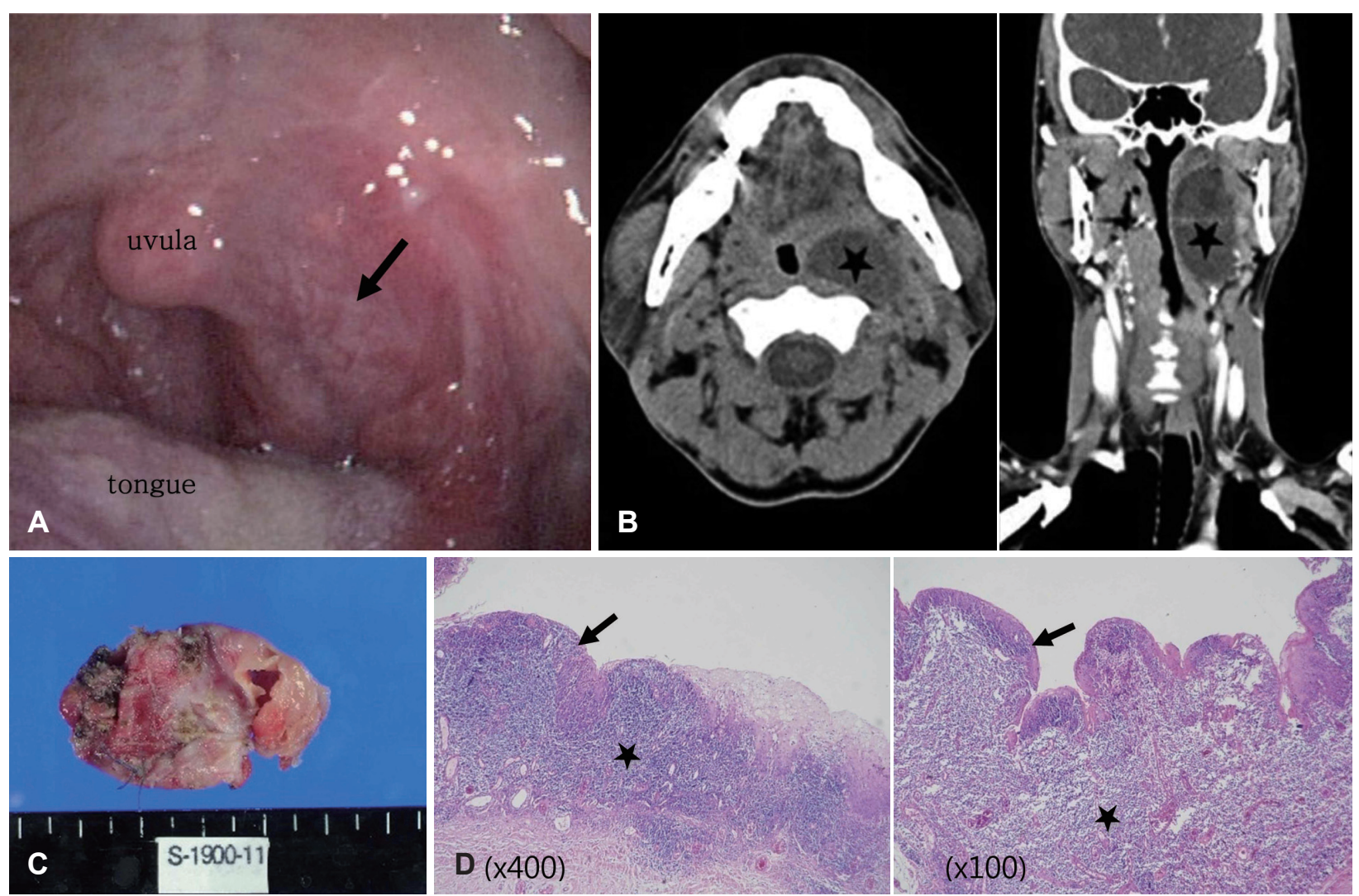

Fig. 1. Oral cavity picture shows lateral wall of left oropharynx was severely protruded and pushed to the center (arrow) (A). Neck CT image showed that the entirety of left parapharyngeal space was filled with cystic lesion (black star) (B). Gross shows cutting in the form of $4 \times 3 \times 0.5 \mathrm{~cm}$ sized cystic structures and the mucosa tissue showed to be inflamed and it is partly observed like a rice-sized feature $(\mathrm{C})$. Histopathological examination (H-E stain) shows cyst is lined by squamous epithelium (arrow) and abundant lymphoid tissue (black star) is observed beneath. Consistent with branchial cleft cyst (D).

pharyngeal wall (Fig. 1A). There were no findings related to damage to vagus nerve or hypoglossal nerve. Furthermore, there were no abnormal findings in nasopharynx, hypopharynx, larynx, and neck.

Neck CT image showed that the entirety of left parapharyngeal space was filled with cystic lesion that had relatively clear boundary with surrounding tissues in the size of around $3.5 \times$ $2.5 \times 6.5 \mathrm{~cm}$ (Fig. 1B). Fine needle aspiration biopsy confirmed that liquid in light yellow was absorbed while no abnormal findings were confirmed in microbiological examination or cytological examination.

Excision of cyst was performed in incision of left oropharyngeal membrane under general anesthesia. After mouth opening by Digman's mouth gag, the incision on lateral side of the tonsil was done and cyst was resected by mosquito and small hemostat. The cyst could be completely eliminated via oral approach because the adhesion was not severe. As the surgery was performed, cyst was located in the left parapharyngeal space and had the simple shape that had no structure such as connected sinus tract.
Cutting in the form of $4 \times 3 \times 0.5 \mathrm{~cm}$ sized cystic structures in gross biopsy, the mucosa tissue showed to the inflamed and it is partly observed like a rice-sized feature (Fig. 1C).

Histopathological examination after the surgery showed that inner cavity side of cystic wall was covered with squamous epithelium and that infiltration of lymphatic tissue was found in the layer below such squamous epithelium, which resulted in diagnosis of branchial cleft cyst (Fig. 1D). The patient was discharged from the hospital without any neurologic disorder or complications. For two years until recently, the patient has been monitored in outpatient follow-up without any findings of recurrence.

\section{Case 2}

A female patient aged 57 was transferred to this hospital for main complaints of left throat pain that had continued for several months. Due to severe throat pain, dysphagia, fever, and general myalgia, the patient visited other hospital to receive the procedure of repeated aspiration and drainage under the diagnosis of abscess in left tonsil several months ago. After- 
ward, the patient showed some improvements. When the patient visited this hospital, physical examination showed the findings of cystic enlagment in the left tonsil with tenderness. Neck CT image showed small cystic lesion in the size of around $1.1 \times 0.8 \times 1.3 \mathrm{~cm}$ that was limited within the left tonsil (Fig. 2). Fine needle aspiration biopsy confirmed that liquid in dark brown was absorbed while no abnormal findings were confirmed in microbiological examination or cytological examination.

Left tonsillectomy and the excision of cyst were performed through oral cavity under the diagnosis of second branchial cleft cyst that occurred in tonsil. When the surgery was performed, cyst was found to occur inside tonsil and to extend toward space in the peritonsillar space. As cystic wall was preserved without any damage to blood vessel or nerve, cyst was completely removed along with tonsil.

According to histopathological examination after the surgery, the patient was diagnosed with branchial cleft cyst. For two years until recently, the patient has been monitored in outpatient follow-up without any complications or findings of recurrence.

\section{Case 3}

A male patient aged 46 was transferred to this hospital for main complaints of edema on the left-lateral pharyngeal wall and repeated abscess that had continued for several months. The patient visited other hospital to receive tonsillectomy due to frequent tonsillitis for several years. When the patient visited the hospital, physical examination showed that left-lateral pharyngeal wall was protruded and pushed outward and that uvula was dislocated to the right (Fig. 3A). However, no abnormal findings were confirmed in nasopharynx, hypo-
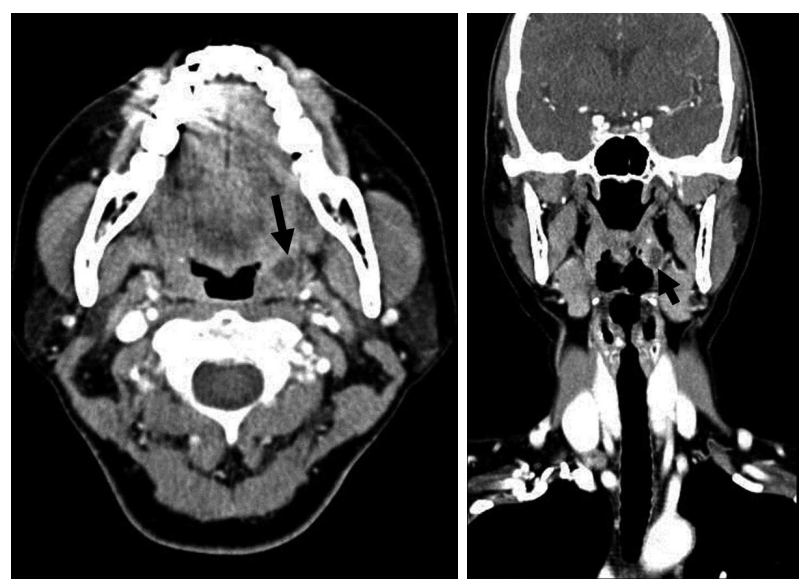

Fig. 2. Cystic mass was observed inside the left tonsil according to neck CT image (arrow). pharynx, and larynx.

According to neck MRI T2-weighted image, cystic lesion in the size of around $2.0 \times 1.8 \times 3.0 \mathrm{~cm}$ was observed to show high signal intensity in the left parapharyngeal space (Fig.
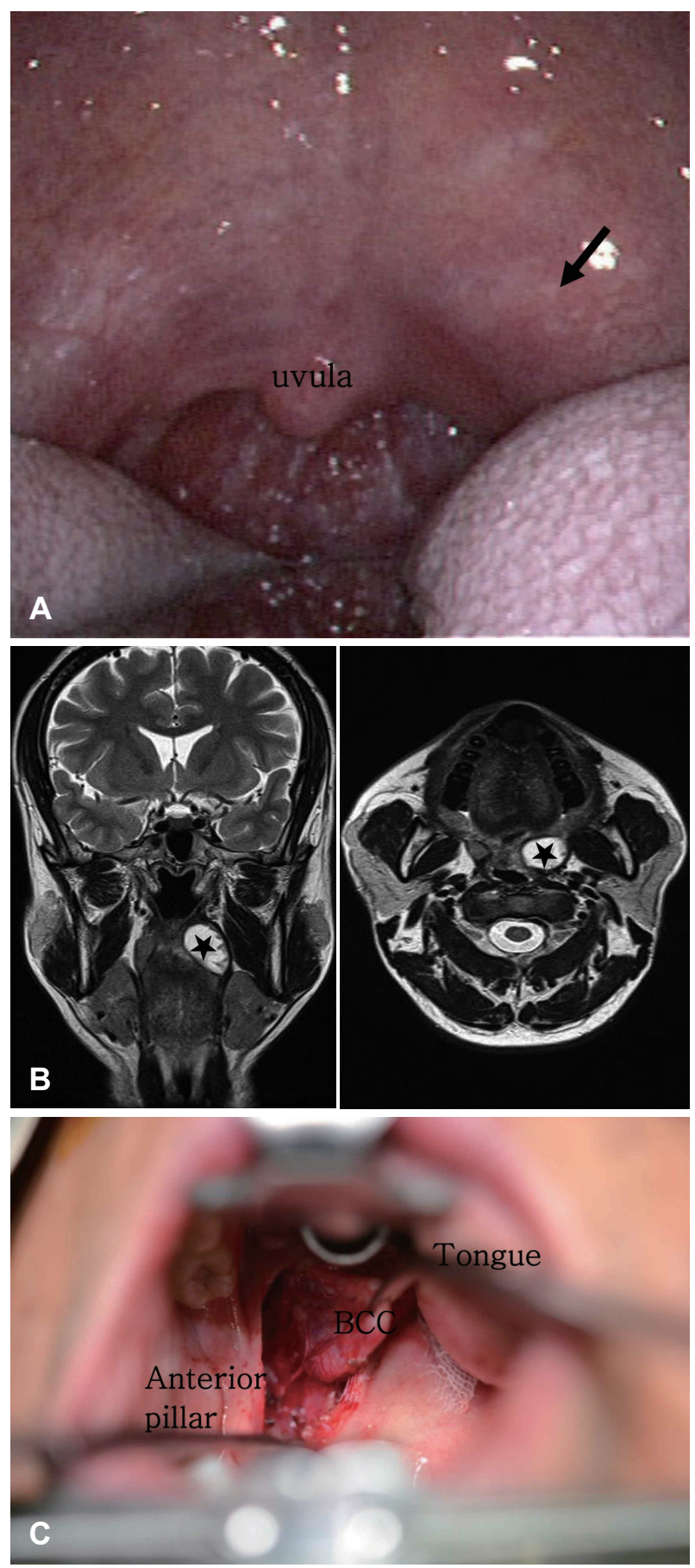

Fig. 3. Oral cavity picture showed that left-lateral pharyngeal wall was protruded and pushed outward and that uvula was dislocated to the right (arrow) (A). Neck MRI T2-weighted image shows $2.0 \times 1.8 \times 3.0 \mathrm{~cm}$ sized cystic lesion is high signal intensity in the left parapharyngeal space (black star) (B). Excision of cyst was performed in intraoral approach. As cystic wall and pharyngeal membrane were preserved, cyst was completely removed (C). 
3B). In fine needle aspiration biopsy, mucus discharge was absorbed, whereas malignant cell was not observed.

Excision of cyst was performed in intraoral approach under the diagnosis of second branchial cleft cyst that occurred in parapharyngeal space. When the surgery was performed, cyst was found to have severe adhesion with its surrounding tissues due to the previous tonsillectomy and repeated incision and drainage. As cystic wall and pharyngeal membrane were preserved, cyst was completely removed without any damage to blood vessels or nerves (Fig. 3C).

After histopathological examination after the surgery, the patient was diagnosed with branchial cleft cyst. For two years until recently, the patient has been monitored in outpatient follow-up without any complications or findings of recurrence.

\section{Discussion}

Second branchial cleft is known to be the most common among such abnormalities. ${ }^{1)}$ The abnormalities of second branchial cleft can be classified to cyst, sinus and fistula depending on connection with skin or pharynx. Among such abnormalities, cyst is the most common. In most of the cases, second branchial cleft cyst is characteristically found in the shape of neck mass along with the anterior border of sternocleidomastoid muscle. ${ }^{4)}$

However, it is a rare case where second branchial cleft cyst is found in place other than such path. As mentioned in these cases, it is a much more rare case where symptom is revealed as repeated abscess in parapharyngeal space among adults. Symptom of parapharyngeal branchial cyst is mostly insignificant. Cyst getting bigger puts pressure on the surrounding area, which causes dysphagia and dysarthria. ${ }^{5,6)}$ In addition, cyst located in opening of eustachian tube may cause hearing loss, whereas if cyst is small in size, symptom itself is mostly insignificant. ${ }^{7)}$ However, all of the patients in these cases were diagnosed with abscess in parapharyngeal space to receive the procedure of incision and drainage when they initially visited hospital. Therefore, it is required to pay attention to diversity of symptoms when branchial cleft cyst appears in parapharyngeal space.

Three types of major tumors in parapharyngeal space include salivary gland tumor that occur in deep parotid gland, schwannoma and paraganglioma. Also, rarely lymphoma, branchial cleft cyst, neurofibroma, inflammatory pseudotumor and lipoma can occure. Tumor in deep lobe parotid gland is most common, if cystic mass exists in parapharyngeal space, it is the most necessary to distinguish it from cystic schwannonoma, minor salivary gland tumor and branchial cleft cyst. ${ }^{89}$

The basic principle is that all of the methods to treat abnormalities of branchial apparatus are a complete surgical removal for the purpose of the prevention of recurrence. ${ }^{10)}$ To this end, it is required to examine detailed medical history of a patient and perform physical examination prior to surgery. It is also necessary to investigate the relation between anatomical location of the lesion and its surrounding structures based on examinations such as neck CT, MRI and fistulography. ${ }^{11)}$ It is useful to distinguish from cystic lesion by MRI finding which says a well marginated, homogenous, cystic mass. If the cyst is infected, a thin rim of enhancement is possible. Another advantage of the MRI may be distinguished from deep lobe parotid lesions and primary parapharyngeal space lesions, it is helpful to determine the surgical approach in accordance with the position of the lesion. ${ }^{12)}$ Surgical approach generally includes transoral approach and transcervical approach or transparotid approach. ${ }^{9)}$ The choice of surgical approach depends on the tumor size, location, vascular status and the degree of suspicion of malignancy. Approach through neck provides a wide view and enables an easy operation of surgical instrument. Therefore, the approach has the strong point that it is convenient to stop bleeding. However, if cyst is located inside internal carotid artery, approach to neck requires dissection of internal carotid artery and vein in order to secure a precise location of cyst. Manipulation of lingual nerve, hypoglossal nerve and superior laryngeal nerve that are located on the path of the approach may cause unexpected complications after surgery. ${ }^{13,14)}$ Although the transoral approach has a high risk of bleeding and recurrence, ${ }^{8}$ in three cases because of the small size of the cyst and an enough operation field of view the author used transoral approach to avoid risk to damage to blood vessels and nerves and to prevent scar on neck. Without any complications, the authors removed all of the cysts successfully. In other report also, transoral approach was used. However, there was no case where transoral approach was used for patient who received incision and drainage due to repeated abscess just as this case. It is believed that delicate surgical manipulation enables overcoming the issue with bleeding and high recurrence rate that have been recognized as risk factors to transoral approach.

Genuine branchial cleft cyst is covered with stratified squamous epithelium cell in around $90 \%$ of the cases and cylinder epithelium in $10 \%$ of the cases. There exist many lymphocytes and aggregate of lymphatic tissues under epithelial tissue, 
which are the characteristic findings of branchial cleft cyst. ${ }^{15)}$ According to histopathological examination, such findings are confirmed in all of the cases in this paper.

Second branchial cleft cyst, which is revealed in the form of cystic mass in parapharyngeal space, is misdiagnosed as abscess in parapharyngeal space, which leads to late diagnosis in many cases. Consequently, cyst has severe union with its surrounding tissues due to repeated infection and incision \& drainage, which may lead to delay in diagnosis and treatment just as the cases in this paper. Therefore, it is necessary to include second branchial cleft cyst when differential diagnosis is performed for cystic mass in parapharyngeal space. If a precise radiological examination and physical examination are performed prior to surgery, it is believed that second branchial cleft cyst in parapharyngeal space can be completely removed in transoral approach without any post-operative complications or scar on neck. Hence, the authors reports the cases along with literature review.

\section{REFERENCES}

1) Drumm AJ, Chow JM. Congenital neck masses. Am Fam Physician 1989;39(1):159-63.

2) Tae K, Jeong SW, Lee EJ, Lee SH, Kim KR, Park CW, et al. A clinical study of branchial anomaly. Korean J Otolaryngol-Head Neck Surg 2002;45(10):998-1003.

3) Zadvinskis DP, Benson MT, Som PM, Smoker WRK. Embryology and congenital cystic lesions. In: Som PM, Curtin HD, editors. Head and neckimaging. St. Louis: Mosby;1996. p.754.

4) Mitroi M, Dumitrescu D, Simionescu C, Popescu C, Mogoantă C, Cioroianu L, et al. Management of second branchial cleft anomalies. Rom J Morphol Embryol 2008;49(1):69-74.

5) Sobol SM. Benign tumors. In: Thawley SE, Panje WR, editors. Comprehensive Management of Head and Neck Tumors. Philadelphia: WB Saunders;1987. p.1353-83.

6) Gatot A, Tovi F, Fliss DM, Yanai-Inbar I. Branchial cleft cyst manifesting as hypoglossal nerve palsy. Head Neck 1991;13(3):24950.

7) Günerí A, Günbay MU, Günerí EA, Ceryan K, Sütay S. Management of parapharyngeal space cysts. J Laryngol Otol 1994;108(9):795-7.

8) Miller FR, Wanamaker JR, Lavertu P, Wood BG. Magnetic resonance imaging and the management of parapharyngeal space tumors. Head Neck 1996;18(1):67-77.

9) Saussez S, De Maesschalk T, Mahillon V, Filleul O, Louryan S. Second branchial cyst in the parapharyngealspace: a case report. Auris Nasus Larynx 2009;36(3):376-9.

10) Chandler JR, Mitchell B. Branchial cleft cysts, sinuses, and fistulas. Otolaryngol Clin North Am 1981;14(1):175-86.

11) The Korean Society of Head and Neck Surgery. Head and Neck surgery. 1st ed. Seoul: Hankook Medical Publishing Co;2000. p.193-8.

12) Shin JH, Lee HK, Kim SY, Park HW, Khang SK, Choi CG, et al. Parapharyngeal second branchial cyst manifesting as cranial nerve palsies: MR findings. AJNR Am J Neuroradiol 2001;22(3):510-2.

13) Ostfeld EJ, Wiesel JM, Rabinson S, Auslander L. Parapharyngeal (retrostyloid)--third branchial cleft cyst. J Laryngol Otol 1991;105 (9):790-2.

14) Papay FA, Kalucis C, Eliachar I, Tucker HM. Nasopharyngeal presentation of second branchial cleft cyst. Otolaryngol Head Neck Surg 1994;110(2):232-4.

15) Choo MJ, Kim YJ, Jin HR. A case of second branchial cleft cyst with oropharyngeal presentation. J Korean Med Sci 2002;17(4): 564-5. 